\title{
Non-Force Character of Systematic Totality in the Context of Informational Form of Matter Motion
}

\author{
Jury F. Abramov and Olga V. Bondarenko* \\ Irkutsk State University \\ 3 Karl Marx Str., Irkutsk, 664003, Russia \\ Irkutsk State Agrarian University \\ Molodezhny, Irkutsk Oblast, 664038, Russia
}

Received 10.11.2016, received in revised form 16.03.2017, accepted 20.03.2017

It is shown that the informational form of the motion is a kind of exchange processes; it acts as a formative factor of substance-energetic cooperation, which allows disposal of the contradiction between the substrate and the functional descriptions of reality. Information form of matter motion appears as a change of the form of system's ordered links and forms of system's communication with the environment, therefore, a change in the system integrity occurs as a result of non-force interaction..

Keywords: system, informational form of matter motion, scientific worldview, non-force interaction.

DOI: 10.17516/1997-1370-0053.

Research area: philosophy.

\section{Introduction}

As for today, the information has got the status of, if not a philosophical, then at least a general scientific category. In the evolution theory the concept of "information" in science manifested a kind of antireductionist position. Understanding the information as an attribute of social and communicative processes, starting with the spoken language and including a variety of IT-solutions, spread to the area of animate and inanimate nature. The result, i.e. the study of complex open systems, cannot be justified and explained without understanding the information as a factor of their structure genesis.

Informational approach to knowledge and scientific view of the information aspects of reality are logical-theoretical abstractions that were developed by science to describe an unusually broad scope of reality, which in accordance with modern theoretical concepts cannot be identified with the earlier well-known characteristics of existence such as mass and energy. In this regard, there is an urgent need to clarify the nature of the information traffic on the level of physical reality, its possibilities and limitations.

(C) Siberian Federal University. All rights reserved

* Corresponding author E-mail address: ov-bond@yandex.ru 


\section{Theoretical framework}

Taking a methodological approach to distinguish the information form of movement of physical reality objects, we follow a number of scientists (B.M. Kedrov, B.V. Akhlibinskii, M.V. Kuznetsov, B.Ia. Pakhomov, and others). The basic concept for our research is the forms of matter motion.

In its most developed form, the concept of motion forms is represented in the works of B.M. Kedrov, which became the basis for the classification of sciences. Undoubtedly, one of his achievements is the introduction into traditional scheme of the relationship of motion forms the concepts of "abstract" (micro-mechanical, macromechanical, thermodynamics, cybernetics) and "specific" (sub-atomic-physical, chemical, biological, social) forms of movement (Kedrov, 1962, 1971).

In terms of the proposed logic it can be said that signs of abstract forms of motion exist in the information forms of physical objects' motion, too. Moreover, it is necessary to bear in mind that these are real physical systems, i.e. non-linear, non-equilibrium. In this case, there is a group of similar processes, namely, the change in the form of system ordered communications and form of system communication with the environment, i.e., change of the integrity depending on the external environment, with its own non-force interaction"symbolic" determination

\section{Discussion}

Basing on the fact that the form of motion in the first approximation can be defined as the organization of stable relations between the interacting objects, which in the second approximation is determined by the relevant laws, we will focus on this issue in more details. In the light of modern science, especially highenergy physics, and synergy, we can say that the concept of motion forms is directed towards the removal of contradictions between the substrate and the functional descriptions of reality. It is of crucial importance to identify the communication material (real-energetic) and information aspects of interaction, taking into account dual-unified (material and ideal) nature of the information.

The notion of informational form of motion appears as common invariant with relation to various specific manifestations of information movement. The concept of "informational form of motion" includes, at least, all kinds of anti-enthropy variations in the reflection as an attribute of matter. Moreover, this concept has a great heuristic potential. In this connection it is necessary to identify special features of the informational form of motion in physical processes.

From this point of view the attention is attracted by the concept of "interchange", reflecting the high prevalence of the metathetical processes in nature and society. In science the concept of "interaction" is also extended and reflects at least a wide range of social and natural processes. In the case of exchange and cooperation in the event there is a mutual transfer of motion. At the same time, if the exchange is accompanied by reacting as a cause of one of the consequences, then in conjunction the action is moved to the fore, as movement has its own material carrier. These concepts are similar, but not identical, and have some extra components. It turns out that systematization of scientific worldviews is sustained by an idea of information exchange (as transmittable, communicative side of reflection), leading to inadequate changes of material-energy costs.

The basis of the modern scientific view of the world is the idea of symmetry at the macroand micro-levels of physical reality. Let us recall that the concept of symmetry is related to the spatial configuration, which stands (at least, for the idealized objects) as expression of the unity of 
dynamic determination and non-force (logically self-consistent genesis of the object is expressed mathematically by variable topology), which we correlate with information. At the same time the elementary particles of matter are considered as binding elements ("bridges") between individual quasi-closed macrocosms, or as some kind of independent space-time "leaves" of the Universe (Vitol, 2012). Interpretation of all the currently known physical interactions necessarily includes the concept of "exchange" interaction, in which the "exchange elements" (quarks, gluons, virtual bosons, mesons, photons, etc.) appear as a manifestation of the collective nature of the particle interaction with the physical environment (vacuum). However, the only "true" elementary particles can be attributed to their fields, while "composite" particles are regarded as the result of the interaction.

Moreover, elementary particles "structuring" is not similar to the earlier known structures. "If we follow the modern theory, the nucleon 'consists' of not only n-mesons but also of nucleonantinucleon pairs of ( $\mathrm{N}$ and $\tilde{\mathrm{N}})$; the electron in its "composition" also contains electron-positron and even nucleon-antinucleon pairs; meson "consists" of three mesons, etc. It is a situation not previously known to atomism and it happens that the particles are composed from each other and the bigger one may be in the smaller one" (Bogoliubov, Shirkov, 2000). If the whole in any case is not the arithmetic sum of its parts, then the microphysical whole has another special properties that are absent in the macrophysical whole. For example, it cannot be presumed that only the atom has such qualitatively different features, but any of its parts do not have these features. Atomic parts actually exist only in the presence of the atom itself. In "free, not bound state they mutate, transform into objects, some properties of which (such as weight) are different from the characteristics of atomic parts. No less important is the fact that modern physics attributes the characteristics of photon to the conditions of its birth, and the terms of its future absorption, i.e. without a definite possibility to be absorbed eventually no one photon could be born" (Kokkede, 1997).

The hierarchy of these forms of matter (motion) is the result of their own development, where forms-elements are linked with the appropriate exchanges into forms-systems, which are elements of the higher level systems. Concurrently, the external exchanges, linking the elements to each other, in one way or another, change the forms, or their movement, and become the internal exchange of system formed by them, ensuring the stability of the new form, in its turn changeable under external influence. In addition, if the exchange between material forms alters their shapes, then it controls the movement in a non-force manner.

Recurring stable interaction of forms becomes regularity of their movement, i.e. the objective norm of self-control, or controls one of the system (or subsystem) elements, wherein the system as the environment of elements selects them basing on their resistance to interactionsexchanges between the elements themselves, which is provided by an optimal combination of stability-variability of these forms for the environment, by pairing their internal and external exchanges.

Selecting and transforming thematerial forms through their exchanges, the environment thus not only controls the movement of its formative components, but also their development. Growth of intensity and variety of exchange processes in the environment due to the quantitative and qualitative development of its constituent forms activates the selection and transformation, not only accelerating their development, but also increasing the value of variability in provision of sustainability. 
Taking into account the above-mentioned considerations, it can be assumed that the informational form of motion appears as a kind of exchange processes, manifested through collective (cooperative) changes of integrity in the process of interaction with the environment, acting as the molding of material-energetic interaction.

Thereby, the informational form of motion characterizes a new type of relationship between the elements of the system - compartment connection. In the methodological and epistemological terms, this means that the information form of the motion does not imply the nature of its material carrier (like other abstract forms of motion), but only the type of connection between the system elements, which in this case act as compartments - coordinated parts, and with the environment. So, the new type of communication is resonance, coherent connection.

In this sense there is a solid philosophical predecessor of synchronization concept, consistency of all processes. G. Leibniz's brilliant idea about the possible existence of significantly non-force interaction becomes fundamental justification, e.g. for the facts of exact "phasing" of coherence phenomena at the macro- and microlevels.

Information as an attributive property of matter is associated with irreversibility, nonlinearity of real processes. It finds rationale in the framework of a constructive use of modern logical-mathematical methods applied to the ideas of the historical evolution of physical objects - the construction of scenarios of potentially possible lines of system evolution (such as microobjects, as well as Metagalaxy) at bifurcation points.

Synergetics and nonlinear macrophysics proved the existence of the so-called emergent direction changes during the process, presenting a strange attractor as "informational processor for storage, transmission and compression of information" (Nicolies, 1986). There appear more and more supporters of integration with genetic ("historical") aspects of systems formation, believing that cooperative processes, order, and self-organization cannot be more or less adequately presented without non-force, informational interactions.

In this regard, of particular interest is the possibility of significant turn of physics to the study of informational form of the physical objects' motion, playing a kind of an essential role in relation to the mass-energy characteristics.

Based on the concept of emerging integrity and counter reduction, the improved deterministic framework is created, according to which there is a mutual two-sided determinism of opposite direction. In the direction from the parts to the whole (bottom-up) determination takes place in accordance with the fundamental forces of physics, in the opposite (the emergent) direction it acts a kind of informational causality.

Cognition of the informational aspects of reality is due to the production of multivalued context of object behavior, in which the determining factors are not separate elements, but rather the connections between them. Subject of cognition, proceeding from the multi-valued context of the object's holistic image differentiates high and improbable connections between the elements and thus builds a probabilistic forecast. However, any attempt at explication of the object's integrity in its entire ambiguity (in context behavior) by applying logical-symbolic means, providing selection and hierarchical subordination of connections and relations, acting as a description of the informational motion, leads to some loss of comprehensive integrity. Thus, the multivalued context of object behavior and logical-symbolic explication are, in our opinion, in a state of degenerate subsidiarity. 
The latter significantly differs from quantum-mechanical complementarity, characterizing the two equal sides of the physical reality. In other words, a comprehensive description of the object's integrity at the system explication level inevitably appears as degenerate. Due to the principal unpredictability of the motion trajectory for the open system undergoing bifurcation, the occurrence of a particular dynamic structure is determined not only by the properties of elements and the system as a whole, but also by external factors. However, the potential abilities of motion are limited by the same factors. Therefore, we can suppose that every possible trajectory of movement bears information about an object's integrity but in the "dumped" form. And each particular embodiment of the object's motion simulated path is a visible form of deep content, arising out of the process non-linear nature.

This circumstance allows describing informational form of motion using symbolic language of models of "random walks" across the field of the possible, implementing the same integrated structural-functional relationship in various ways: the approximation process to the development (quasi-stable) state by creating different scenarios of selfstructuring and overstructuring the field of evolution possible ways. In this case, while constructing of the specific scenario of the system evolution (setting the initial conditions of the resonant coupling with environment), the choice of the evolution approximating path (minimum inertial variety, to which the trajectory, having passed its bifurcation point, belongs) means that alternative, additional ways (without which there is no integrity) become indistinguishable, i.e. they exist, but in a degenerate state. This indicates that the concept of informational form of the motion enables considering a particular path of the system development in relation to the entire spectrum of evolutionary ways as being in relation to degenerate complementarity.

\section{Conclusion}

In this way, we have grounds to assert that the informational form of motion appears as an attribute of physical processes, presenting the evolution of systems as a complexification of informational and realenergy components.

As regards to the specific communication of informational form of motion with a specific carrier, it can be said that it is consistent with the concept of abstract forms of motion, as it takes into account only the type of connection between the system elements and shows the relative indifference in relation to the material carrier. The higher is the step of nature development, the greater is the relative indifference.

Through the "prism" of informational form of motion, complex, hierarchically ordered systems are viewed anew. The informational form of motion acts as restrictive and permissive capabilities of evolution and not only evolution of physical reality. The latter is particularly evident at the social level, up to the system of ideas about humans and their rights as the highest value within a human rights approach to human potential development (Chuksina, 2015). It permits identifying new non-force nature of the systematic totality, contributing to the development of a holistic evolutionary worldview, thereby reviving and expressing (for objects of physical reality - in a strict logical and mathematical form) presentations of ancient philosophers ("everything is united", "a part of the whole is in everything") on a new scientific conceptual basis. 


\title{
References
}

Bogoliubov, N.N., Shirkov, D.V. (2000). Quantum fields. Moscow, 234 p.

Chuksina, V.V. (2015). State specialized bodies for the promotion and protection of human rights. Moscow, Publishing house Yurlitinform, 18-19.

Kedrov, B.M. (1971). Criteria for distinguishing between higher and lower forms of motion. Space, time, motion. Dialectical materialism and natural science. Moscow, Nauka, 326-343.

Kedrov, B.M. (1962). The subject and the relationship of natural sciences. Moscow, Publushing House of Academy of Sciences of the USSR, 412 p.

Kokkede, Y. (1997). The theory of quarks. Moscow, $164 \mathrm{p}$.

Nicolies, J.J. (1986). Dynamics of Hierarchical Systems: An Evolutionary Approach. Berlin, 3.

Vitol, E.A. (2012). The evolutionary nature of macro-microsymmetric universe, In Philosophy and cosmology, 1 (10), 52-64.

\section{Несиловой характер системной тотальности \\ в контексте информационной формы \\ движения материи}

\author{
Ю.Ф. Абрамов, О.В. Бондаренко \\ Иркутский государственный университет \\ Россия, 664003, Иркутск, ул. Карла Маркса, 3 \\ Иркутский государственный аграрный \\ университет \\ Россия, 664038, Иркутская обл., \\ Иркутский р-н, пос. Молодежный
}

\begin{abstract}
Показано, что информационная форма движения является видом обменных процессов; выступает формообразующей вещественно-энергетического взаимодействия; позволяет снять противоречие между субстратным и функииональным описанием реальности. Информационная форма движения материи проявляется как изменение формы упорядоченности связей системы и формы связи системы со средой, следовательно, происходит изменение иелостности системы в результате несилового взаимодействия.
\end{abstract}

Ключевые слова: система, информационная форма движения материи, научная картина мира, несиловое взаимодействие.

Научная специальность: 09.00.00 - философские науки. 